\title{
O AGRESSOR E AS CIRCUNSTÂNCIAS DIANTE DAS RELAÇÕES ABUSIVAS SOB A PERSPECTIVA DA GESTALT-TERAPIA
}

\author{
THE AGGRESSOR AND THE CIRCUMSTANCIES FACING ABUSIVE RELATIONS \\ FROM THE PERSPECTIVE OF GESTALT-THERAPY
}

\author{
Bianca Gracher ${ }^{1}$ \\ Luzia de Miranda Meurer ${ }^{2}$
}

RESUMO: A relação abusiva pode ser considerada como o excesso de poder e de controle, na objetificação do outro, independente da violência aplicada (física, psicológica, sexual e outras) e do tipo de relação afetiva. Assim, esse estudo tem como objetivo desvelar as circunstâncias presentes nas relações abusivas em relacionamentos íntimos heteroafetivos, tendo em vista a figura do agressor na perspectiva da Gestalt-Terapia. Dessa forma, o estudo não tem como intuito justificar, mas sim compreender esses atos. A esse respeito, correlacionando o tema à abordagem gestáltica, a qual se baseia na visão do homem como um sujeito em relação com o mundo, que só pode ser apreendido por meio de um olhar holístico e um indivíduo que busca equilíbrio e autorrealização, organizando-se naturalmente para alcançar suas preferências e satisfazer suas necessidades mediante as transições com o meio. A esses fatores, buscou-se responder ao seguinte problema de pesquisa: é possível desvelar o fenômeno das relações abusivas em relacionamentos íntimos heteroafetivos, tendo em vista a figura do agressor, na perspectiva do olhar da abordagem da Gestalt-Terapia? Nesse sentido, a partir da abordagem qualitativa, foi realizada uma pesquisa de revisão bibliográfica nas bases de dados científicas, nas plataformas online. Desse modo, os resultados apresentados nas unidades de análise demonstraram que mediante algumas circunstâncias, encontram-se: uso de drogas, visão estereotipada da figura masculina, falta de informações frente às leis e consequências diante dos atos abusivos praticados, falta de contato consigo, dificuldades de expressão verbal e emocional, ajustamento disfuncional, entre outros. Considera-se então que o sujeito que comete atos violentos, pode apresentar sofrimento psicológico e falta de clareza em relação às consequências de seus atos e também a falta de contato consigo e com o meio.

Palavras-chave: Agressor. Circunstâncias abusivas. Relações abusivas. Gestalt-terapia.

\footnotetext{
I Graduanda do curso de Psicologia da UNIFEBE. E-mail: biagracher97@gmail.com

2 Graduada em Psicologia pela Universidade Federal de Santa Catarina e mestra em Educação pela Fundação Universidade Regional de Blumenau. Atua como psicóloga clínica e docente no Curso de Psicologia do Centro Universitário de Brusque-UNIFEBE.E-mail: luzia.meurer@unifebe.edu.br
} 
ABSTRACT: The abusive relationship can be considered as an excess of power and control, in the objectification of the other, regardless of the applied violence (physical, psychological, sexual and others) and the type of affective relationship. Thus, this study aims to unveil the circumstances present in abusive relationships in intimate heteroaffective relationships in view of the aggressor's figure from the perspective of GestaltTherapy. Thus, the study is not intended to justify, but rather to understand these acts. In this regard, correlating the theme to the gestalt approach, which is based on the view of man as a subject in relation to the world, which can only be apprehended through a holistic look, and an individual who seeks balance and self-realization, organizing naturally to achieve your preferences and satisfy your needs through transitions with the environment. To these factors, we sought to answer the following research problem: Is it possible to unveil the phenomenon of abusive relationships in intimate hetero-affective relationships in view of the aggressor's figure, from the perspective of the GestaltTherapy approach? In this sense, from a qualitative approach, a literature review research was carried out in scientific databases on online platforms. Thus, the results presented in the units of analysis showed that under some circumstances, there are: drug use, stereotyped view of the male figure, lack of information regarding the laws and consequences of abusive acts committed, lack of contact with you., difficulties in verbal and emotional expression, dysfunctional adjustment, among others. It is then considered that the subject who commits violent acts may present psychological suffering and lack of clarity regarding the consequences of their acts, as well as the lack of contact with themselves and with the environment.

Keywords: Agressor. Abusive circumstances. Abusive relationships. Gestalt therapy.

\section{INTRODUÇÃO}

Esse estudo foi realizado a partir de uma revisão bibliográfica, para desvelar as circunstâncias presentes nas relações abusivas em relacionamentos íntimos heteroafetivos tendo em vista a figura do agressor na perspectiva da Gestalt-Terapia. Ao considerar que o aporte teórico da Gestalt-Terapia, aponta em seu bojo conceitual o olhar ao indivíduo e sua natureza como um todo. Nesse sentido, não diz respeito só ao homem, seu comportamento ou suas patologias, mas sim a uma visão holística do mundo no qual esse mesmo homem, não pode ser pensado abstratamente ou isoladamente.

Dessa forma, primeiramente identificou-se a relação abusiva e seus tipos, no qual pode ser definida por situações que possuem excesso de poder e de controle, na objetificação do outro, podendo a violência ser física, psicológica, sexual, entre outras. Em seguida verificou-se as circunstâncias e seus autores envolto dessas violências, por fim desvelando-se todo esse contexto por meio dos conceitos basilares da Gestalt-Terapia. 
A relevância do estudo, vem ao encontro de assuntos pertencentes aos relacionamentos abusivos estarem ganhando cada vez mais visibilidade, corroborando por meio de dados estatísticos, denúncias e maiores aberturas para o assunto. Sendo assim, por mais que muitos acontecimentos ainda sejam velados, amplamente veiculados na mídia, aqui citando uma matéria publicada pelo portal de notícias online GI, mostrou que em 2020 no Brasil, obteve-se ros mil denúncias voltadas à violência contra a mulher (MARTELLO, 2021).

Diante dessa realidade, esse estudo bibliográfico, visou identificar e elencar conteúdos encontrados nos bancos de dados Scientific Electronic Library Online (Scielo), Periódicos Eletrônicos em Psicologia (PEPSIC) e Google Scholar (Google Acadêmico), a partir das palavras-chaves selecionadas sobre o tema: relações abusivas, motivos para abuso, circunstâncias abusivas e Gestalt-Terapia.

Assim, o sujeito que pratica a agressão, o agressor/abusador, passa a ser o estudo, já que por trás desse indivíduo pode haver histórias, motivações, razões, circunstâncias entre outras possíveis situações que o colocam em tal papel, a partir do momento que é compreendido por meio do seu contexto e realidade.

Por fim, a proposta desse estudo, se direciona a acadêmicos e profissionais de psicologia e para o público em geral que venham demonstrar interesse pelo tema apresentado.

\section{REFERENCIAL TEÓRICO}

O referencial teórico a seguir abrangeu assuntos como relações abusivas, circunstâncias e seus autores e por fim Gestalt-Terapia e seus pressupostos teóricos diante da violência. Buscando responder se é possível desvelar o fenômeno das relações abusivas em relacionamentos íntimos heteroafetivos, tendo em vista a figura do agressor na perspectiva da Gestalt-Terapia.

\section{I Relações abusivas}

Primeiramente é válido compreender o que é uma relação abusiva e exemplos de violência que ocorrem no decorrer da mesma. Dessa forma, compreende-se como relação 
abusiva, aquela que há excesso de poder e de controle, na objetificação do outro (BARRETO, 2015). Leão et al. (2017, p. Io) relatam que uma relação abusiva

[...] é um dos principais métodos utilizados para coibir, repreender e limitar a independência [...] Trata-se de uma relação baseada em laços afetivos com indivíduos que apresentam comportamentos abusivos - desde abuso emocional, verbal, físico, até mesmo sexual. Estas relações são caracterizadas por jogos de controle, manipulação, ciúmes excessivos, violência e frieza emocional. Trata-se de um relacionamento baseado no controle [...] censurando ações e vontades a partir de apelações emocionais em um jogo de sentimentos.

Diante dessa realidade, independente da violência aplicada e do tipo de relação afetiva, Oliveira et al. (2016) complementam que a grande maioria da sociedade, muitas vezes, não possui consciência da ocorrência desses fatos, por visualizar de forma naturalizada, visto que esse olhar pode ser tanto da vítima quanto do agressor. Já Leão et al. (2017) relatam que essa naturalização violenta, decorre da enraização da cultura machista e misógina que frequentemente inferioriza e objetifica as vítimas pelas sociedades patriarcais.

A partir dessa visão, obtendo como foco de estudo o indivíduo do sexo masculino como o agressor nas relações abusivas, pode-se usar como exemplo parceiros afetivos, sejam eles namorados, maridos, noivos ou de qualquer outro vínculo amoroso com a vítima. No qual muitas vezes esse indivíduo, impõe um excesso de poder sobre sua(s) vítima(s), gerando ações mascaradas que ocultam ou podem ser confundidas por meio de justificativas triviais sob a forma de cuidado, preocupação ou qualquer prática de afago. Situações como, monitorar mensagens ou demais ações da vítima em um aparelho eletrônico, supervisionar seus compromissos e práticas do dia a dia, controlar suas vestimentas e demais ações que possam vir a reprimir as escolhas ou condutas dessa mulher (BARRETO, 2018).

Mediante esse contexto, para melhor compreensão, frente aos tipos e exemplos de violência, Lopes (2016) elenca comportamentos que podem ocorrer de tal forma isolada ou associada: a) violência física, compreendida como qualquer conduta que ofenda sua integridade ou saúde corporal, como exemplo: tapas, soco, empurrões, entre outras ações que muitas vezes deixam marcas visíveis; b) violência psicológica, compreendida como qualquer conduta que lhe cause danos emocional e diminuição da autoestima, que lhe prejudique e perturbe o pleno desenvolvimento, que visa degradar ou controlar suas ações, 
comportamentos, crenças e decisões, mediante ameaça, constrangimento, humilhação, manipulação, isolamento, vigilância constante, ou qualquer situação que possa causar prejuízo à saúde psicológica da vítima e c) violência sexual, compreendida como qualquer conduta que constranja ao presenciar, manter ou a participar de relação sexual não desejada, mediante intimidação, ameaça, coação ou uso da força física, que induza a comercializar ou a utilizar, de qualquer modo, a sua sexualidade, ou realizar qualquer ação sexual sem sua vontade própria ou consentimento.

Além desses três tipos principais de violência, Fonseca, Ribeiro e Leal (2012) acrescentam a existência de outros dois, sendo eles: a violência patrimonial e a violência moral. A primeira, cujo a violência patrimonial, refere-se à destruição, retenção ou subtração tanto parcial quanto total de bens materiais, objetos, documentos pessoais ou demais valores e direitos do outro, exemplos como, domínio sob o dinheiro, estelionato, privação de bens, entre outros. Já a violência moral, caracteriza-se como qualquer conduta que configure calúnia, difamação ou injúria, exemplos como acusações, críticas mentirosas, exposição referente a vida da vítima, rebaixar e/ou desvalorizar o outro.

Cabe salientar que esses fatores de violências não possuem um público-alvo específico. Cruz et al. (2018) trazem o fato que as mesmas podem ocorrer indiferentemente de raças, religiões, culturas, escolaridade, entre outros. Porém, Barreto (2018) pondera que grupos de idosos, crianças, pessoas com deficiência e principalmente mulheres, são mais vulneráveis a serem vítimas de violência.

Assim, Oliveira et al. (2016) discorrem que essas vítimas são vistas como mais vulneráveis, vem em decorrência de um consumo cultural em que o sexo masculino foi decretado como o dominador, sendo aquele que protege a família, o lar, mantém as finanças da casa e dispõe de maior força física. Fatores como esses, que corroboram com a matéria publicada pelo portal de notícias online GI, no qual anunciou que em 2020 no Brasil, obteve-se 105 mil denúncias voltadas a violência contra a mulher, registradas pelo Ligue 180 e pelo Disque ıoo, que são os canais de denúncias voltadas a violação de direitos humanos (MARTELLO, 202I). Observa-se então, uma alta demanda, necessitando estudos e políticas de prevenções frente a essas violências. 
Dessa forma, tendo em vista o conceito de relação abusiva, as possíveis violências aplicadas e seu público-alvo, cabe considerar a partir desses, a origem dos atos, ou seja, as circunstâncias que levam um sujeito a praticar as mesmas.

\subsection{Relação abusiva: circunstâncias e seus autores}

O desejo de compreensão aos autores de violência, vem ao encontro do que a psicóloga Beco (2015 apud LEAL; ALMEIDA, 2020) discorreram, em que olhar, cuidar e acompanhar o autor, é proteger diversas vítimas, no âmbito social e o próprio indivíduo atuante. Ponderam as mesmas autoras, que esses indivíduos não são seres anormais ou que apresentam deformidades, mas sim seres humanos capazes de cometer atos perversos. Além disso, Oliveira (2019) enfatiza que a visão de uma pesquisa ao autor de violência, não tem como intuito justificar atos violentos cometidos, mas sim compreender os nexos essenciais que eles empreendem nas relações violentas.

Assim, como pontua Furniss (1993 apud OLIVEIRA, 2016) não será estereotipando, punindo, ou tomando somente ações negativas, que as práticas violentas podem vir a desaparecer e as situações ilegais se tomarem por resolvidas. Também é importante, levar em consideração um olhar ao sujeito, sua história de vida, significações sociais, seu modo de ser e viver.

A esse respeito, cabe considerar que apesar da violência nas relações abusivas derivar do desejo de poder, domínio e demais fatores que levam o outro a um papel de inferioridade, a mesma pode estar relacionada a uma manifestação de fraqueza, diante de um descontrole do sujeito que a pratica, não encontrando uma maneira ou demais formas de expressão que possam substituir essa ação agressora (MUSZKAT, 2016). Por entender que o indivíduo em estado de fragilidade, não tende a agir de forma coesa, compreendendo também as consequências que seus atos podem vir a tomar.

Nesse sentido, os mecanismos de comunicação (modos de expressões) e os papéis de poderes (questões de desigualdade e hierarquias) relembram a influência diante da cultura, no que tange em respeito aos gêneros, como exemplo, homens que utilizaram por muitos anos a violência como forma de resolução de diversos acontecimentos. Ou seja, a violência por sua vez pode ser considerada uma espécie de herança familiar, em que é possível ter acesso desde o início da vida do sujeito, visualizando e vivenciando conflitos familiares 
e/ou sendo passivo de atos abusivos (OLIVEIRA, 2019). Reis, Ramos e Cavalcante (2015) complementam esse olhar ao indivíduo do sexo masculino, pelo mesmo carregar uma herança histórica aliada aos estereótipos sociais centrados na dominação masculina sobre a mulher.

Por conseguinte, Hirigoyen (2006, p. 75) acrescenta que

[...] historicamente, o homem sempre foi considerado o detentor único do poder, $\mathrm{e}$ as mulheres sempre se viram excluídas dele, isso condicionou o modo de pensar de ambos, desde o berço: é assim, porque sempre foi assim! Essa representação social, partilhada por todos, ainda mantém os estereótipos, apesar da evolução dos costumes

Segundo Leal e Almeida (2020) a educação também está associada às questões circunstanciais, ao qual a hereditariedade e a tradição contribuem ao caráter desse sujeito. Para melhor compreensão, o exemplo de uma criança criada em um lar que visualiza o pai como símbolo responsável e dominante pelo ambiente, em que esse pai realiza atos como gritar ou bater na esposa e/ou filhos rotineiramente, apresentando como comuns, os atos à figura masculina.

As mesmas autoras ponderam que esse contexto também pode estar vinculado à história desse pai, que vivenciou essas práticas anteriormente quando criança, associando e realizando essa forma de educação como uma herança doméstica. Porém, é válido ressaltar que toda criança que vier a vivenciar atos como tais, não se tornará necessariamente um reprodutor dos mesmos atos visualizados, ou que isso venha a ser um determinante exclusivo. Há que se levar em consideração, somente quando um sujeito vier a praticar atos de violência.

Outro aspecto relevante, seria o uso de drogas lícitas e ilícitas, principalmente em maior destaque, o uso do álcool, caracterizado como uma droga lícita, que tem sido frequentemente relacionado ao comportamento violento (LEAL; ALMEIDA, 2020) e que se destaca nos resultados das pesquisas desse estudo.

Diante disso, Gonzatto (2019) discorre que historicamente, o álcool está inserido na sociedade há milhares de anos, onde o sujeito busca pelo prazer momentâneo e apesar de ser considerado prejudicial e ter se tornado um problema de saúde pública, sabe-se que o consumo tem aumentado demasiadamente nos últimos anos e com isso, crescendo os 
episódios de violência causados pelos agressores alcoolistas. Assim sendo, observa-se que a busca pelo prazer vem aumentando, o que faz refletir o que há por trás dessa procura.

No entanto, quando se trata de fatores psicológicos que podem ser os causadores dessa busca pelo prazer diante do álcool, Souza, Menandro e Menandro (2015) trazem como principais aspectos, a fuga de problemas, carências de autoestima, falta de perspectivas para o futuro, fraquezas psicológicas em geral e dificuldades de se expressar.

Já Soares et al. (2017) em uma pesquisa referente a motivações ao consumo de álcool, trazem um resultado de ioo pessoas que se propuseram a responder o questionário ofertado, dispondo como resultado, interação com colegas, distração de uma situação/problema, alívio de tensão/stress, questões de lazer, expectativa em algo positivo e o aumento de confiança com outras pessoas.

Nessa pesquisa, o uso de bebidas alcoólicas obtém maior dominância em caráteres sociais (festas...), no qual o sujeito realiza essa ação em influência ao processo de socialização, sem visualizar as consequências que o álcool ingerido pode vir a causar em seus atos (ficar violento).

Além dessas vulnerabilidades, também se ressalta a falta de informações diante das leis e consequências de tais atos abusivos, causa no qual vem ao encontro do sujeito agressor visualizar as práticas abusivas como ações comuns.

Como exemplo, Oliveira (2019) relata a fala de um indivíduo denunciado por abuso de ato sexual em sua pesquisa, em que o mesmo afirma ser inocente, porque apenas realizou toques no corpo da vítima, indicando não ser claro para si o que é o abuso sexual, algo que transcende o uso da força ou de fato a penetração sexual. Outro exemplo, em uma pesquisa de Totten (2003 apud TONELI et al., 2010), envolvendo 30 homens em situação de marginalidade econômica, que praticavam violência contra namoradas, o autor verificou que a maioria dos agressores não reconhecia seus atos como ilegais, mas sim como medidas educativas.

Frente a todos esses aspectos, cabe compreender a partir de um olhar atento e empático, a singularidade de cada indivíduo, seu contexto e aspectos históricos, atuando como possíveis fatores aos motivos e/ou circunstâncias que levaram o mesmo a cometer abuso nas relações afetivas. Portanto, esse olhar pode ser realizado à luz da GestaltTerapia. 


\subsection{Gestalt-terapia: pressupostos teóricos diante da violência}

Tomando por referência a visão gestáltica, é fundamental compreender primeiramente seu conceito. Sendo uma abordagem psicológica surgida nos anos 50, inicialmente pensada por Fritz Perls, a partir de críticas à psicanálise, obtendo como diferencial a autopercepção (NASCIMENTO; VALE; 2013).

A mesma baseia-se na visão do homem, sendo um ser responsável e digno de confiança, capaz de escolher, responsabilizando-se por suas escolhas e tendo por isso liberdade para mudá-las. Também um sujeito em relação com o mundo, que só pode ser apreendido por meio de um olhar holístico e um indivíduo que busca equilíbrio e autorrealização, organizando-se naturalmente para alcançar suas preferências e satisfazer suas necessidades mediante as transições com o meio. Consequentemente um sujeito que busca respostas existenciais para suas vivências, encontrando-as apenas no seu momento experiencial presente e um ser voltado para a consciência, ou seja, atento ao mundo que o cerca e a si mesmo (CANEDO, 1997).

Frente a isso, em um de seus conceitos, encontra-se o termo contato, no qual é definido de acordo com D'Acri, Lima e Orgler (2007) como a comunicação que ocorre entre o indivíduo e o ambiente que o cinge, tendo assim, uma perspectiva holística na qual o organismo e meio são um todo indivisível. Sendo assim, é por meio desse conceito que Ribeiro (2016), discorre que o sujeito chega mais próximo de si mesmo, pois somente assim será capaz de realizar e compreender suas opções e por fim, a partir desse contato consigo, vem a nascer as possibilidades de contatos com o mundo.

Partindo desse contexto, Cardella (2002 apud LOUZEIRO, 2018) traz que é na fronteira de contato que ocorrem as obstruções, os impedimentos e problemas na relação do eu com o outro, os quais impedem o processo de crescimento do sujeito, não havendo um ajustamento criativo saudável e sim um contato tóxico. Cabe salientar, que o ajustamento criativo, conforme Ribeiro (2016) é um processo no qual o corpo-pessoa utiliza de sua espontaneidade natural para encontrar a autorregulação nas soluções disponíveis, às vezes não claras, em si mesmo, no ambiente ou em ambos.

Exemplificando melhor, é quando a vítima está em uma situação na qual pode não visualizar uma saída, por existir um medo desconhecido ou uma situação em que muitas 
vezes pode impedir da mesma procurar por ajuda. Sendo assim, considera-se que esses contextos e tudo que ocorre no organismo em qualquer momento, advém de um campo, conceituado como campo fenomenológico, ou também como campo fenomenal. Sendo aquele onde o meio e o comportamento se unem, resultando sua totalidade, ocorrendo na particularidade de cada indivíduo, podendo ou não corresponder à realidade objetiva (RIBEIRO, 1985).

Sob essa visão, Ribeiro (1985, p. 5I) enfatiza e completa:

[...] todo comportamento, sem exceção, está inteiramente em função do campo fenomenológico, onde o organismo atua. O campo fenomenológico consiste na totalidade de experiências das quais a pessoa toma consciência no momento da ação. Essa tomada de consciência pode variar de um nível mais baixo a um mais elevado, embora se presuma que nunca possa chegar a ser completamente inconsciente.

Sendo assim, Machado e Macedo (2019) trazem que o olhar deve ser singular para cada indivíduo e suas vivências. No entanto, o recurso da redução fenomenológica com propósito de tematizar a consciência pura, torna-se fundamental para se compreender o sofrimento causado para gerar algum tipo de violência, uma vez que, para cada indivíduo os atos violentos praticados podem possuir significâncias diferentes.

Pondera as mesmas autoras que, a violência é uma figura inacabada ${ }^{3}$, sendo ela aquilo que prende a atenção. Assim, ao ocorrer a fronteira de contato, pode ocasionar a dificuldade que muitos indivíduos têm de procurar por ajuda, desde notar/perceber seus atos aplicados, até a continuação dos mesmos, possuindo uma resistência à tomada de consciência desse processo.

\section{PROCEDIMENTOS METODOLÓGICOS}

A natureza da pesquisa se deu de forma básica, com intuito de conhecimento científico, sem interesses em desenvolver processos ou produtos comerciais, onde de acordo com Gobbo (2017), a pesquisa básica tem por intuito produzir conhecimentos e teorias, buscando pela clareza do tema a ser pesquisado.

\footnotetext{
${ }^{3}$ Figura inacabada é definida quando um indivíduo se relaciona com outros sem vitalidade, estando a energia bloqueada por situações mal resolvidas, consequentemente nomeadas como inacabadas (CIORNAI, I995, p. 5).
} 
Quanto à abordagem do problema, seguiu de maneira qualitativa por ter como modo de análise um campo voltado às ciências sociais e obter uma verificação subjetiva dos dados, também assumindo como objetivo de estudo, uma pesquisa exploratória, a fim do aprimoramento de ideias e busca de conhecimento, aproximando a temática com a realidade dos indivíduos (GIL, 2010).

Frente aos procedimentos técnicos, a pesquisa foi caracterizada como revisão narrativa, ao qual consiste em analisar as obras existentes na literatura, principalmente livros e artigos científicos, acerca do fenômeno pesquisado, sobre uma temática mais ampla, a partir da interpretação e crítica dos autores, não contendo critérios rigorosos para sua produção (CORDEIRO et al., 2007).

Portanto, para responder à pergunta problema e os objetivos desse estudo, a coleta de dados foi realizada em plataformas científicas como Scientific Electronic Library Online (Scielo), Periódicos Eletrônicos em Psicologia (PEPSIC) e Google Scholar (Google Acadêmico), mediante as seguintes palavras-chaves: abusador, motivos para abuso, circunstâncias abusivas, relações abusivas e relação abusiva Gestalt-Terapia. As palavras foram pesquisadas de forma individual, entre aspas e em pares, para refinar mais precisamente os artigos relacionados com o tema da pesquisa.

Diante da pesquisa nas bases de dados, a data de publicação dos materiais foi delimitada aos artigos que corresponderam ao período de 2015 a 2021, tanto da área da psicologia quanto das demais, contendo no título ou resumo uma das palavras-chaves selecionadas, que envolveram relação com o tema e artigos limitados ao português e inglês.

Os dados foram analisados a partir da Análise Temática (AT), configurada como um método qualitativo de análise de dados encontrados em uma pesquisa. Consiste em, a partir do estudo, identificar quais foram os conteúdos ou fenômenos que emergiram, realizando uma análise interpretativa dos mesmos (SOUZA, 2019). Também, por meio da criação de 3 unidades de análise.

Possuindo como método de exclusão, caso na base de dados repita artigos já contemplados, que corresponda aos anos anteriores a 2015, que não possua as palavraschaves selecionadas em seu título, resumo ou relação ao tema, como também artigos que discorrem em outras linguagens que não sejam de idioma português ou inglês. 
Além dos artigos selecionados por meio das bases de dados pesquisadas, utilizou-se obras já publicadas sem restrições de data de publicação, de autores de grande relevância sobre o tema e artigos presentes na biblioteca pessoal da autora, que provém para o conjunto de conhecimento abordado nesse estudo.

\section{ANÁlise dos RESULTADOS}

Apresentam-se nesse estudo, as análises dos resultados obtidos frente ao tema dessa pesquisa. Sendo assim, para desvelar o fenômeno estudado, sendo ele as circunstâncias presentes nas relações abusivas em relacionamentos íntimos heteroafetivos, tendo em vista a figura do agressor na perspectiva da Gestalt-Terapia, foi criada três unidades de análise, sendo elas: a violência e as relações abusivas, seus tipos e públicos-alvo. Em sequência, a figura do agressor, seu histórico e circunstâncias e por fim, a violência na ótica do agressor na perspectiva da Gestalt-Terapia em seus conceitos basilares.

Nesse horizonte, de acordo com a primeira unidade de análise referente a violência e as relações abusivas, junto aos seus tipos e públicos-alvo, levando em conta os dados levantados, conforme Lopes (2016) o olhar frente ao assunto demonstra ser atual, sejam as violências sexuais, psicológicas, físicas, morais e patrimoniais, contra os públicos de crianças, idosos, mulheres ou qualquer vítima que esteja envolta a esse cenário.

Paralelamente, em específico nas relações abusivas com casais heterossexuais, sendo o agressor masculino para com a vítima do sexo feminino, visualizou-se principalmente as violências psicológicas, morais e físicas. Apesar dessas práticas violentas ainda serem visualizadas de forma naturalizadas e até mesmo romantizadas, tanto pelo agressor, quanto pela vítima. Sendo essas ações confundidas com carinho, amor e/ou cuidado. Assim, podendo se tornar algo rotineiro, comum e até mesmo levar cada vez mais a situações extremas e não saudáveis aos envolvidos (BARRETO, 2018).

Em suma, as relações abusivas em geral são por si uma violência, a qual vem cada vez mais transparecendo por meio de denúncias e falas sobre o assunto em questão. Visualizar o assunto em noticiários, roda de conversas, grupos de apoio, entre outros meios de comunicação, colabora na divulgação do tema e até mesmo na ideia de apoio às vítimas e na desconstrução e apoio aos autores. 


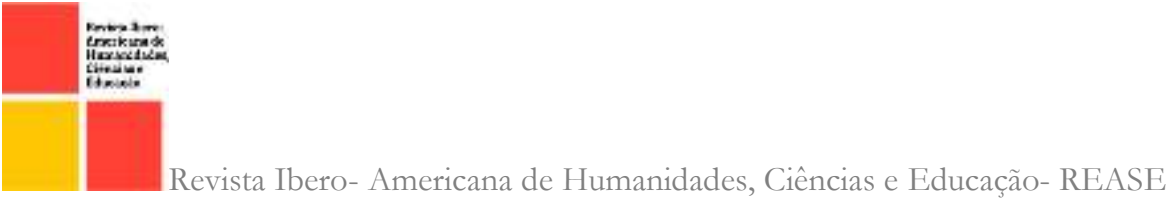

Frente a isso, inicia-se a segunda unidade de análise referente à figura do agressor, seu histórico e circunstâncias. Visto que, o olhar ao autor dos casos de relações abusivas, até os tempos atuais, não é um tema de prioridade ou de materiais disponíveis ao acesso público e geralmente estão centradas no levantamento estatístico, que priorizam dados demográficos, como: idade, relação de parentesco em relação à vítima, atendimentos submetidos, entre outros. No entanto, quando abordado características qualitativas, normalmente são encontradas em alguns parágrafos ou meros capítulos de materiais (artigos, livros e/ou demais publicações) com temas principais voltados à vítima de relações abusivas.

Nessa concepção, os motivos e/ou circunstâncias que levam aos atos podem estar associados a um conjunto de elementos de sentidos subjetivos, referentes à história individual de cada sujeito e/ou ao contexto sociocultural. Sendo assim, como principais resultados de pesquisa entre as bibliografias, (OLIVEIRA, 2016, 2019; REIS; RAMOS; CAVALCANTE, 2015; HIRIGOYEN, 2006; LEAL; ALMEIDA, 2020; GONZATTO, 2019; SOARES et al., 2017; TONELI et al., 2010) trazem como possíveis relações aos motivos e/ou circunstâncias dos atos abusivos praticados, a figura masculina como fato histórico, o uso de drogas lícitas e ilícitas, principalmente com foco no álcool e a falta de informações frente às leis e consequências diante dos atos abusivos praticados.

A esse respeito, cabe considerar que apesar do intuito dessa pesquisa visualizar o autor da violência com filtro de gênero, sendo a figura masculina, nota-se de fato que as pesquisas resultam em sua maioria, os mesmos como principais agressores. Circunstância essa na qual Hirigoyen (2006, p. 75) discorre que o sexo masculino historicamente carrega crenças a linguagens, exemplos como: homens não choram, homem é o chefe da família, homem necessita estar em posição de poder, homem é mais forte, entre outras falas que discorreram ao longo das gerações e levaram a um consumo cultural essa figura como dominadora, consequentemente estando a par da violência em que enfatiza e agrega a promoção desse papel dominador. Essas colocações incorporam a questão da masculinidade, na qual o sujeito utiliza essas falas e/ou práticas para a sustentação de uma imagem. Imagem essa que pode levar o mesmo a seguir um padrão para se sentir parte dos estereótipos de gênero. 
Dessa forma, conhecer as representações sociais dessa figura masculina enquanto dominadora e ainda passível de atos abusadores como comuns, viabiliza a compressão das formas dos sujeitos pensarem, sentirem e agirem, considerando que são elementos de uma trama social em que existem constantes trocas simbólicas e afetivas, sendo de fato uma possibilidade de resposta ao que se questiona nessa pesquisa. Pois repensar a masculinidade/figura masculina, faz parte do repensar sobre o cuidado consigo e com o outro.

Identificou-se também, como um motivador à violência a presença do álcool enquanto uma droga lícita, sendo ele o principal elemento presente e interligado aos fatos abusivos, como exemplo, em uma pesquisa realizada por Souza, Carvalho e Teodoro (2012 apud GONZATTO, 2019) referente a qualidade de vida e depressão em mulheres vítimas de violência, identificou-se que $70 \%$ dos agressores eram alcoolistas e o motivo que elas referiam como sendo um dos principais causadores da agressão, era o uso de álcool realizado pelo agressor.

Frente a esses aspectos, apesar do álcool ser considerado em grande escala um dos principais motivadores da violência, é de extrema importância compreender o que se encontra por trás desse vício, na qual esse agressor busca pelo prazer, esquecimento, tranquilidade e sacio de suas necessidades, em que possui como consequência os atos violentos que podem vir ao encontro dos desejos inibidos. Essas questões são levantadas, trazendo como resultados algumas carências, frustrações, crises, problemas com expressões verbais e emocionais, quesitos sociais, entre outras questões psicológicas.

Identificou-se também como um motivador para atos violentos, a falta de informações diante das leis e consequências aos atos abusivos. Esse fator vem ao encontro do olhar do agressor frente aos seus atos, quando esse indivíduo compreende serem atos comuns, aceitáveis e justificáveis. Assim, notou-se em demais pesquisas como a de Oliveira (2019), essa escassez da compreensão do que equivalem ou não a prática abusiva, na qual atua como possível mecanismo para que outras práticas venham a ocorrer. Pesquisas essas que indicam nos seus resultados em falas como: "eu não cometi abuso sexual, apenas foram alguns toques”, "eu não teria atacado ela se não parecesse que ela queria algo a mais, "não considero a minha pena justa e não sei direito o que aconteceu, não fiz nada demais". 
Enfim, tais reflexões demonstraram ser os principais resultados da segunda análise demandada. Assim em sequência, iniciando a terceira e última unidade de análise em relação a violência na ótica do agressor na perspectiva da Gestalt-Terapia em seus conceitos basilares.

Sendo assim, elencou-se 4 pressupostos teóricos da Gestalt-Terapia para correlacionar com o tema estudado. Primeiramente analisando a teoria de campo, em que Aguiar (2012, apud. LOUZEIRO, 2018) traz que a mesma aponta o mundo que o sujeito vive como parte dele, ou seja, é considerar todas essas normas sociais, culturais vigentes, possibilidades e demais causas apontadas na sociedade como parte desse indivíduo, as quais ecoam no seu modo de contatar a si, o outro e o mundo. Assim, o homem e a realidade estão integrados e é justamente esse caráter relacional que o acompanha, permitindo suas mudanças.

Frente a essas colocações, compreende-se que o indivíduo agressor se constitui nesse campo, naturalizando as situações violentas e não obtendo visão sobre as consequências possíveis, conforme relatado anteriormente, referente as ações confundidas com amor, carinho e ações não visualizadas como incorretas. Por assim dizer, o estereótipo da masculinidade é aplicado no decorrer de suas experiências.

Por conseguinte, visualizando o ajustamento criativo, sendo conforme Ribeiro (2016) uma autorregulação do indivíduo, ocorreria se no campo for ensinado de outra forma as questões desse estereótipo da figura masculina, em que ao invés de ser dito que a figura masculina deve ocupar papéis de dominância, for discursado que homens podem chorar, expressar suas angústias, estarem no mesmo nível econômico que outras mulheres e entre outras afirmações que poderiam levar a outro contexto. Porém, no estado do ajustamento disfuncional, ocorre essa naturalização, como exemplo de não expressar seus sentimentos de uma forma saudável, acumulando suas angústias e até mesmo esse acúmulo se tornando uma expressão violenta.

Assim, essas considerações se correlacionam com o contato, conceito esse que por D’Acri, Lima e Orgler (2007) seria como a comunicação que ocorre entre o indivíduo e o ambiente que o cinge, no qual em prática o indivíduo agressor, não possui um contato com o ambiente que o norteia, nem consigo mesmo. Consequentemente invadindo um outro sujeito, situação a qual ocorre na fronteira de contato, definida por Cardella (2002 apud 
LOUZEIRO 2018) que é onde ocorrem as obstruções, os impedimentos e problemas na relação do eu com o outro, no entre eu-outro-mundo. Exemplificando melhor, esse indivíduo agressor não possui contato consigo, muito menos um cuidado, obtendo percepções distorcidas de si, do outro e do ambiente, de modo a ser improvável transferir um cuidado ao outro, com a presença dessa barreira, assim, havendo a violência na fronteira.

Mediante esse contexto, é por meio do contato que a relação com o mundo pode ser nutritiva e saudável, assim, somente entrando em contato consigo será possível esse agressor visualizar os motivos e circunstâncias que o levaram a tais práticas, permitindo responsabilizar-se diante de suas experiências, também possibilitando um processo de desconstrução.

Considerando então, foi possível por meio dessas três unidades de análise, o desvelamento desse estudo, primeiramente compreendendo o que é essa relação abusiva, sendo ela uma prática de violências que objetifica o outro, como ocorre as violências, por meio de ações verbais, físicas, morais, entre outras, se aplicando as mulheres, crianças e idosos, os alvos mais vulneráveis. Em seguida as circunstâncias por trás desses atos, como o histórico da figura masculina, a utilização do álcool e a falta de informação frente às leis e enfim a perspectiva da Gestalt-Terapia frente ao assunto, utilizando seus conceitos basilares, como o contato, o ajustamento criativo e disfuncional, o conceito de campo e a fronteira de contato.

Desvelando-se assim, que o agressor ao longo de sua história não teve inteiramente consciência de si e de seus atos, no qual não realiza o contato consigo, consequentemente não fazendo o contato com o meio. Considerando que é na relação que tudo acontece, primeiramente ele aplica a violência consigo e após com o outro.

Outrossim, cabe considerar nesse contexto, que para si, o agressor está aplicando um modo funcional, ou seja, está suprindo seu desejo de poder, porém para o meio e para com a vítima, um processo totalmente disfuncional. Nesse entendimento, como para cada indivíduo a violência pode ter uma significância distinta, para ele acaba se naturalizando sendo seu ponto de resolução de conflitos.

Também é importante relembrar que para a Gestalt-Terapia, o indivíduo é um ser particular e único, o qual possui suas potencialidades, assim sendo, possível esse homem 
vivenciar sua masculinidade de outras diversas maneiras. Onde diante das relações, possui suas opções de escolhas, as quais deve responsabilizar-se de modo a que as contatem ao meio. Apesar dessa etapa acontecer somente a partir da sua tomada de consciência frente à violência e de fato quando romper suas crenças e conceitos passados em sua vida. Pois o agressor que realiza a repetição de seus atos e funcionamento, não tende a trazer novas formas de existir, sendo um indivíduo limitado.

Embora nunca se esteja pronto, sendo sempre possível se atualizar, pois todos os seres estão em processos, vivendo em um campo, se constituindo e se construindo a todo momento, a partir de cada relação estabelecida com o mundo. Por fim, é possível visualizar o quão necessário e importante é refletir e compreender o papel do agressor diante desses contextos em que muito se estuda a posição e proteção da vítima. Porém, também o papel da psicologia frente a essa temática, por olhar de forma mais humana para todo histórico, motivos, circunstâncias e demais casos da vida de cada ser humano envolto ao contexto da violência.

\section{CONSIDERAÇÕES FINAIS}

As considerações finais a seguir abrangeu os fatores analisados, as contribuições desse estudo e sua relevância, relembrando o objetivo do mesmo e alguns dos métodos aplicados.

Deste modo, o presente estudo teve por objetivo, desvelar as circunstâncias presentes nas relações abusivas em relacionamentos íntimos heteroafetivos, tendo em vista a figura do agressor na perspectiva da Gestalt-Terapia. Uma vez que, entender um pouco mais sobre esse sujeito, pode-se também contribuir com a proteção no contexto da violência.

Os resultados foram construídos, a partir de uma pesquisa bibliográfica, em que por meio de uma revisão narrativa resultou em materiais favoráveis, com conteúdos relevantes dentro da proposta desse trabalho.

Diante desse contexto, constatou-se que por meio das análises construídas, os fatores foram o uso de álcool, o consumo cultural e a visão estereotipada da figura masculina, a falta de informações frente às leis e consequências diante dos atos abusivos praticados, a fuga de problemas, carências de autoestima, falta de perspectivas para o futuro, 

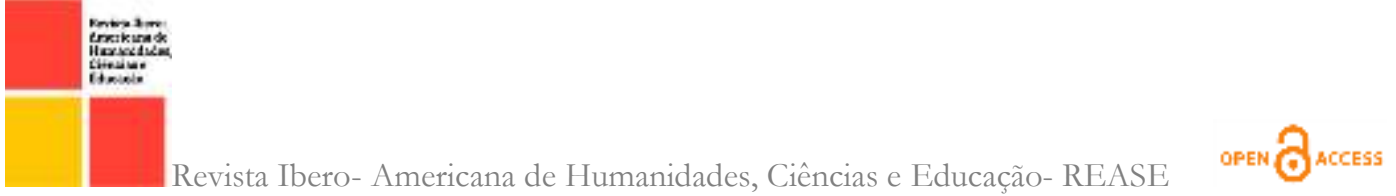

dificuldades de expressão verbal, a falta de contato consigo e com o meio, como também a naturalização da violência de forma funcional para esse indivíduo.

Esses fatores conclusivos, reforçam a ideia que olhar de forma singular para esse sujeito e compreender os nexos essenciais que estão por trás das relações violentas, poderá agregar para proposta de resolução dessas práticas, ao invés de somente estereotipar ou tomar ações punitivas.

Espera-se que esse estudo possa ter contribuído com informações acerca do tema ao leitor, ainda que os resultados bibliográficos consistam grande parte dos estudos com ênfase voltado à vítima das relações. Assim, a relevância ou interesse na história ou motivação do agressor ainda encontra-se em desenvolvimento. Com novas pesquisas, esse tema pode ampliar os conhecimentos aos profissionais da psicologia e demais áreas similares.

Foi de suma importância profissional e pessoal realizar esse trabalho de conclusão de curso nessa temática, que mesmo tão pouco verbalizada e estudada diante do foco apresentado, desde o início da graduação foi apreciada pela primeira autora. Onde, o tema para a pesquisa surgiu em decorrência de um estágio realizado com mulheres vítimas de violência doméstica, em que a mesma teve contato com o assunto, despertando curiosidades, questionamentos e dúvidas sobre a outra perspectiva desse campo. Por fim, verificou-se que é um assunto recente e com especificações em seu foco, averiguando-se contribuir com a compreensão do leitor e a possibilidade de estimular futuros trabalhos frente ao tema.

\section{REFERÊNCIAS}

BARRETTO, Raquel Silva. Psicóloga explica relacionamentos abusivos: o que é e como sair dessa situação. [Entrevista cedida a] Repórter UNESP, Repórter Unesp, São Paulo, ago., 2015. Disponível em: http://reporterunesp.jor.br/2015/o8/20/psicologa-explicarelacionamentos-abusivos-o-que-e-e-como-lidar-com-essa-situacao/. Acesso em: 29 jul. 2021.

BARRETO, Raquel Silva. Relacionamentos abusivos: uma discussão dos entraves ao ponto final. Rev. Gênero, Niterói, v. I8, n. 2, p. I42-154, 2018. Disponível em: https://periodicos.uff.br/revistagenero/article/view/31312. Acesso em: or ago. 2021. 
CANEDO, Ingrid Robinson. Contribuições da Gestalt-terapia para o referencial teórico da orientação profissional. Rev. ABOP, Porto Alegre, v. I, n. I, p. 59-67, jun. 1997. Disponível em: http://pepsic.bvsalud.org/scielo.php?script=sci_arttext\&pid=SI4I4- 8889199700 oroooo5\&lng=pt\&nrm=iso. Acesso em: 25 set 2021.

CIORNAI, Selma. Relação entre criatividade e saúde na gestalt-terapia. Rev. do I Encontro Goiano de Gestalt-terapia, v. I p. 72-75, 1995. Disponível em: http://www.nuted.ufrgs.br/oa/criativas/midiateca/modulo_I/Criatividade_na_perspectiv a_da_Gestalt.pdf. Acesso em: ro ago. 202I.

CORDEIRO, Alexander Magno et al. Revisão sistemática: uma revisão narrativa. Rev.

Col. Bras., v. 34, n. 6, p. 428-431, 2007. Disponível em https://www.scielo.br/j/rcbc/a/CC6NRNtP3dKLgLPwcgmV6Gf/abstract/?lang=pt Acesso em: or ago. 2021.

CRUZ, Juliana Maria et al. Relacionamento abusivo: o silêncio dentro do lado. Cadernos de Artigos, v. 4, n. 2, 2018. Disponível em https://portaldeperiodicos.unibrasil.com.br/index.php/anaisevinci/article/view/ 4278 Acesso em: or ago. 2021.

D'ACRI, Gladys; LIMA, Patrícia; ORGLER, Sheila. Dicionário de gestalt-terapia: "gestaltês". São Paulo: Summus, 2007.

FONSECA, Denire Holanda da; RIBEIRO, Cristiane Galvão; LEAL, Noêmia Soares Barbosa. Violência doméstica contra a mulher: realidades e representações sociais. Psicologia \& Sociedade, Belo Horizonte, v. 24, n. 2, maio/ago. 2012.

Disponível em: https://www.redalyc.org/articulo.oa?id=3093265860o8. Acesso em: 04 ago. 2021.

GIL, Antônio Carlos. Como elaborar projetos de pesquisa. 5. ed. São Paulo: Atlas, 20 Io. 
GOBBO, André. Ciência e metodologia da pesquisa e do trabalho científico. Balneário Camboriú: Faculdade Avantis, 2017.

GONZATTO, Camila. Violência contra a mulher e alcoolismo: quem são as vítimas? 2019. Trabalho de Conclusão de Curso (Bacharelado em Psicologia) - Universidade Regional do Noroeste do Estado do Rio Grande do Sul, Rio Grande do Sul, 2019. Disponível em: http://bibliodigital.unijui.edu.br:8o8o/xmlui/handle/123456789/6645. Acesso em: 04 ago. 2021.

HIRIGOYEN, Marie-France. A violência no casal: da coação psicológica à agressão física. Rio de Janeiro: Bertrand Brasil, 2006.

LEAL, Bianca; ALMEIDA, Andreia Alves de. O início de tudo: o agressor doméstico como vítima do seu passado nos casos de violência doméstica e os métodos que podem ser aplicados pelo judiciário como forma de educação e prevenção. Revista JusFARO, v. 2, n. 2, p. I-I9, dez. 2020. Disponível em: https://revistas.faro.edu.br/JUSFARO/article/view/367. Acesso em: 28 jul. 2021.

LEÃO, Bruna Maques et al. Relacionamento abusivo: o patriarcado e suas influências na atualidade. materializando conhecimentos. Revista Eletrônica, v. 8. 2017. Disponível em: www.colegiomaededeus.com.br/revista/revistacmd_v82017/artigos/ a4_relacionamento\%20abusivo.pdf. Acesso em: I5 ago. 2021.

LOPES, Flávia Marina Capa de Brito. Violência doméstica contra homens: percepções das forças de segurança. 2or6. Dissertação (Mestrado em Psicologia) - Universidade do Minho, Escola de Psicologia, 2016. Disponível em http://hdl.handle.net/r822/43250. Acesso em: 05 ago. 202I.

LOUZEIRO, Teresa Cristina Pereira. As interfaces entre masculinidade e violência contra a mulher: uma perspectiva Gestáltica. 2018. Monografia (Bacharelado em 
Psicologia) - Universidade Federal do Maranhão, São Luís, 2018. Disponível em: https://monografias.ufma.br/jspui/handle/123456789/2344. Acesso em: or ago 2021.

MACHADO, Sabrina Prado; MACEDO, Maria Luisa W. S. O olhar da gestalt-terapia sobre a violência contra mulheres. Boletim Entre SIS, Santa Cruz do Sul, v. 4, n. I, p. 3144, jan./jun. 2019. Disponível em: https://online.unisc.br/acadnet/anais/index.php/boletimsis/article/view/ı466. Acesso em: 29 jul 2021.

MARTELLO, Alexandro. Brasil teve ios mil denúncias de violência contra a mulher em 2020. Gr Política, 07 mar. 2021. Disponível em: https://gi.globo.com/politica/noticia/2021/03/o7/brasil-teve-105-mil-denuncias-deviolencia-contra-mulher-em-2020-pandemia-e-fator-diz-damares.ghtml. Acesso em: 04 ago 202I.

MUSZKAT, Malvina. Violência familiar. São Paulo: Blucher, 2016.

NASCIMENTO, Lázaro Castro Silva; VALE, Kamilly Souza do. Reflexões acerca do fazer ético na clínica gestáltica: um estudo exploratório. Rev. Abordagem Gestalt, vl.19, n. 2, p. 2013. I57-166, Disponível em: http://pepsic.bvsalud.org/scielo.php?script=sci_arttext\&pid=SI809-68672013000200003. Acesso em: 25 set. 2021.

OLIVEIRA, Bruna de Paula. Análise do discurso de detentos por crime sexual contra crianças e adolescentes: uma perspectiva do agressor. 2019. Trabalho de Conclusão de Curso (Bacharelado em Psicologia) - Faculdade de Ciências Biomédicas de Cacoal, Cacoal, 2019. Disponível em: http://repositorio.facimed.edu.br/xmlui/handle/I23456789/III. Acesso em: 03 ago. 2021.

OLIVEIRA, Francisca Moana A. de et al. Romantização do relacionamento abusivo, uma violência silenciosa: a ineficácia da lei Maria da Penha. In: ENCONTRO DE PESQUISA E EXTENSÃO DA FACULDADE LUCIANO FEIJÃO, 9., 2oi6, Sobral. 
Anais [...] Sobral: Faculdade Luciano Feijão, 2016. p. I-I4. Disponível em: https://docplayer.com.br/1395969or-

Romantizacao-do-relacionamento-abusivo-uma-violencia-silenciosa-a-ineficacia-daleimaria-da-penha.html. Acesso em: 30 jul. 2021.

REIS, Daniela Castro dos; BARROS, Arthur Aliverti Saltori de; CAVALCANTE, Lília Iêda Chaves. Agressor sexual de crianças e adolescentes: uma discussão sobre o gênero dos participantes na literatura. Psicologia em Revista, Belo Horizonte, v. 2I, n. 2, p. 252-272, ago. 2015. Disponível em: http://pepsic.bvsalud.org/scielo.php?script=sci_arttext\&pid=SI677II682015000200004\&lng=pt\&nrm=iso. Acesso em: o8 ago. 2021.

RIBEIRO, J. Ponciano. Gestalt-terapia: refazendo um campo. São Paulo: Summus, 1985.

RIBEIRO, J. Ponciano. Vade-mécum de gestalt-terapia: conceitos básicos. 3. ed. São Paulo: Summus, 2016.

SOARES, Fernanda de Jesus et al. Análise dos motivos dos jovens e adultos consumirem álcool. Revista Multidisciplinar e de Psicologia, v. II, n. 35, p. 554-566. p. I98I-II79, maio. 2017. Disponível em: https://idonline.emnuvens.com.br/id/article/view/756. Acesso em: 07 ago. 2021.

SOUZA, Luciana Karine de. Pesquisa com análise qualitativa de dados: conhecendo a análise temática. Arq. Bras. Psicol., Rio de Janeiro, v. 71, n. 2, p. 5I-67, 2019. Disponível em: http://pepsic.bvsalud.org/pdf/arbp/v7in2/o5.pdf. Acesso em: 20 jul. 202I.

SOUZA, Luiz Gustavo Silva; MENANDRO, Maria Cristina Smith; MENANDRO, Paulo Rogério Meira. O alcoolismo, suas causas e tratamento nas representações sociais de profissionais de saúde da família. Physis Revista de Saúde Coletiva, Rio de Janeiro, v. 25, n. $4, \quad$ p. 1335 -1360, 2015. Disponível em: 


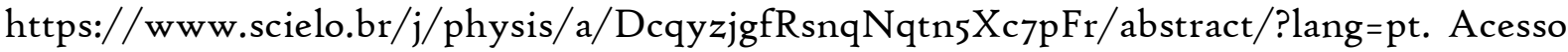
em: 07 ago. 2021.

TONELI, Maria Juracy Filgueiras et al. Atendimento a homens autores de violência contra as mulheres: experiências latino americanas. Florianópolis: UFSC/CFH/NUPPE, 2010. 